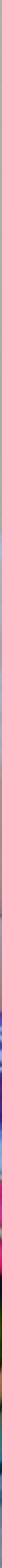




\section{https://doi.org/10.29105/pu8.16-1 \\ PLANEACIÓN ESTRATÉGICA DE INFORMATIZACIÓN EN LOS CENTROS EDUCATIVOS PARA LA CONSTRUCCIÓN DE UNA COMUNIDAD DE APRENDIZAJE}

\section{LUIS JORGE HERNÁNDEZ PALACIOS \\ https://orcid.org/0000-0001-6990-1403}

RESUMEN

Diversos y dinámicos son los factores que intervienen en los entornos educativos para conseguir generar aprendizajes significativos y relevantes ante la sociedad de la información y del conocimiento. Uno de ellos, implantado en los últimos años, ha sido el uso de las herramientas digitales en los quehaceres de la enseñanza. En ello se infiere un acicate para la transformación de las formas organizativas y de construcción en los centros educativos. Bajo este panorama, la integración de las TIC educativas se han integrado en las escuelas y han ido generando lazos de dependencia y colaboración entre los agentes educativos. En estos centros educativos se han desarrollado unas dinámicas que apuntan al reforzamiento de la idea de que las TIC han favorecido la aparición de indicios de que se está construyendo una comunidad de aprendizaje. Cuando se habla de la implementación digital, se habla del uso crítico de las TIC en el que se considera que éstas se utilizan como herramientas cognitivas, es decir, articuladas a un fuerte componente pedagógico y psicológico capaz de contribuir al desarrollo de habilidades de orden superior como razonar, inferir, interpretar, argumentar, proponer, modelar, tomar decisiones, resolver problemas, entre otros. Así mismo, al hacer notable la complejidad social que estos aspectos pedagógicos estimulan en los agentes implicados, la planeación estratégica surge a manera de proposición para hacer frente a la gestión eficaz de esta integración digital y construcción social de las Comunidades de Aprendizaje que satisfagan las necesidades de calidad educativa en materia de equidad, interculturalidad y competitividad global.

PALABRAS CLAVE:

Planeación, Tecnologías, Comunicación, Aprendizaje, Gestión, Innovación
ABSTRACT

Diverse and dynamic are the factors that intervene in educational environments to generate meaningful and relevant learning before the information and knowledge society. One of them, implemented in recent years, has been the use of digital tools in teaching tasks. In this, an incentive for the transformation of organizational and construction forms in educational centers is inferred. Under this panorama, the integration of educational ICTs have been integrated into schools and have been generating bonds of dependency and collaboration between educational agents. In these educational centers, dynamics have been developed that point to the reinforcement of the idea that ICTs have favored the appearance of signs that a learning community is being built. When we talk about digital implementation, we talk about the critical use of ICT in which it is considered that these are used as cognitive tools, that is, articulated to a strong pedagogical and psychological component capable of contributing to the development of higher order skills how to reason, infer, interpret, argue, propose, model, make decisions, solve problems, among others. Likewise, by highlighting the social complexity that these pedagogical aspects stimulate in the agents involved, strategic planning arises as a proposal to face the effective management of this digital integration and social construction of the Learning Communities that satisfy the needs of educational quality in terms of equity, interculturality and global competitiveness.

KEYWORDS:

Planning, Technologies, Communication, Learning, Management, Innovation 
e sabe que la educación pertene-

S ce a un sector que no frecuenta las modificaciones, adaptaciones 0 innovaciones de una forma fácil, inmediata y constante sin previo análisis. No obstante, en la actualidad, los procesos educativos (las metodologías de enseñanza, sus agentes y recursos didácticos) demandan la articulación inmediata con los procesos administrativos (la gestión de recursos, procesos de comunicación globales, desarrollo del capital humano, innovaciones curriculares, entre otros) con la finalidad de alcanzar los estándares de calidad que los usuarios y la sociedad demandan de los centros escolares. Es decir, se requiere de un proceso de administración que contemple como lo señala Chiavenato (2017), el diseño, la organización, la dirección y el control de los recursos con los que se cuentan para alcanzar los objetivos de la organización, en este caso, el centro educativo.

En ello, la educación neoliberal torna de un carácter empresarial al servicio de la enseñanza, perdiendo en sí su esencia: educar para la transformación y el mejoramiento social. En estas las prácticas empresariales, en las que

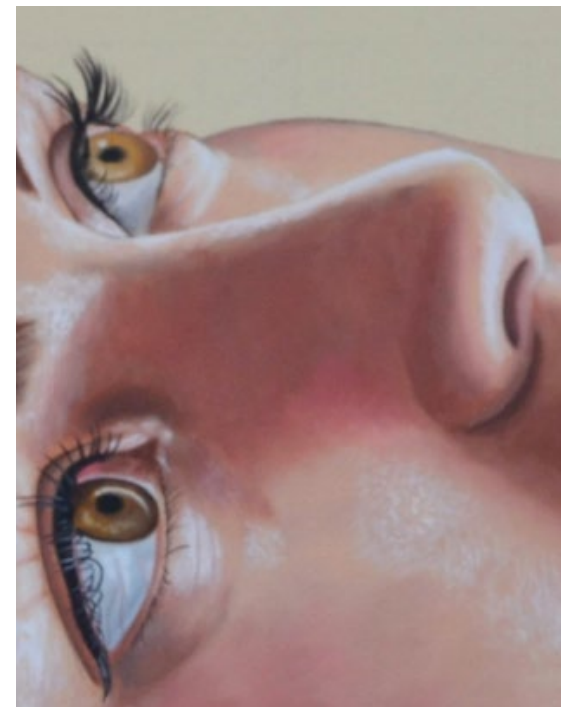

subyacen las convicciones neoliberales, la tarea central de las escuelas no es la educación, sino la capacitación de los educandos en ciertos desempeños de aplicación inmediata, ahora llamadas competencias para la vida social y laboral. Esta formulación de competencias deja de lado la esencia social de la enseñanza ya que elimina las prácticas educativas de formación crítica, creativa y ética porque reduce a las competencias como habilidades y capacidades que se transforman en procedimientos automatizados que el alumno debe memorizar para desplegar en situaciones no inéditas. Es con base en estas premisas que se debe

\section{Hay que considerar la necesidad}

\section{de una alfabetización en medios digitales,}

\section{o bien el desarrollo de criterios para desenvolver}

\section{el sentir crítico ante tanta vorágine comunicativa}

\section{e informativa.}

replantear la reflexión del quehacer educativo en la actualidad y con ello de qué medios dispone para lograr su cometido.

Los centros educativos, como resultado de las evoluciones constantes en los medios de comunicación digitales, presentan un reto en materia de competitividad: mayor demanda en la generación de conocimientos, formación de nuevas habilidades digitales y sociales, externalización y diversificación de los espacios de aprendizaje e involucramiento con su entorno social (comunidad de padres de familia, organizaciones civiles y gubernamentales, entre otras). Hay que considerar la necesidad de una alfabetización en medios digitales, o bien el desarrollo de criterios para desenvolver el sentir crítico ante tanta vorágine comunicativa e informativa. Se hace alusión entonces a contar con parámetros de calidad frente a la cantidad que se extiende a la sociedad con respecto a estos medios digitales de comunicación.

Es por eso, que las herramientas digitales conocidas como TIC (Tecnologías de la Información y de la Comunicación) deben adquirir más presencia en 
las instituciones que pretendan seguir en el mercado actual, en ellas radica el motor de cambio -y con ello adaptación (actualización)- de diversos aspectos de la vida de los actores educativos y de la dinámica social, cultural y política de los propios centros. Sin embargo, uno de los deslices más comunes que se tiene en la adquisición de estos recursos es la falta de orientación pedagógica e institucional que se les asume. Si bien, las TIC son un recurso indispensable y técnicamente ya asumido por la mayor parte del sector educativo, no deberían tornarse como la tónica solutiva ante las nuevas demandas.

Los recursos sin metodología son como las ramillas que crecen directamente del tronco del árbol: le quitan fuerza y no tienen utilidad a medio o largo plazo. La renovación pedagógica centrada exclusivamente en los conqués es necesariamente somera y superficial. Si no va acompañada 0 antecedida de una renovación metodológica centrada en ramas principales (principios y métodos didácticos) y secundarias (técnicas de enseñanza) podrán ser, además, contradictorias por desvirtuar el sentido de desarro-

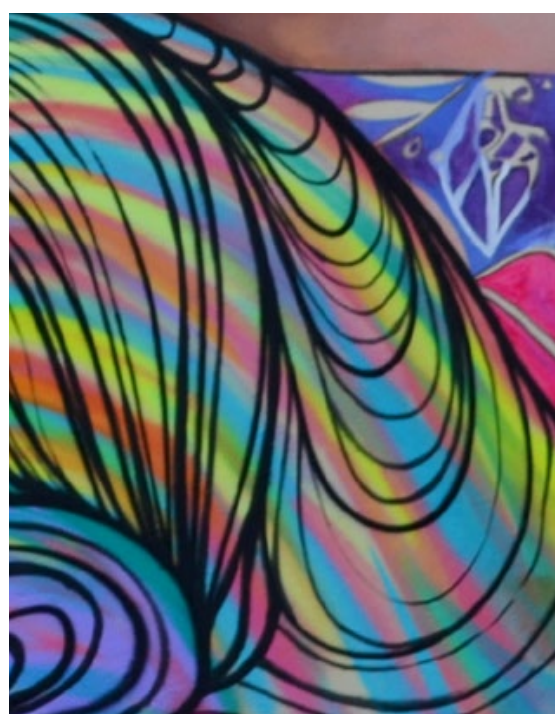

llo del árbol completo (De la Herrán y Fortunato, 2017).

Como infieren los autores Herrán y Fortunato (2017) las adaptaciones tecnológicas en las escuelas carecen de sentido cuando sólo se pretende obtener un indicador a favor de la calidad en materia de infraestructura. Aunado a esto, en las escuelas de todos los niveles encontramos una cantidad significativa de profesores que integran en su quehacer educativo recursos TIC sin una previa formación pedagógica y metodológica, lo que obstaculiza la eficiencia del recurso tecnológico.

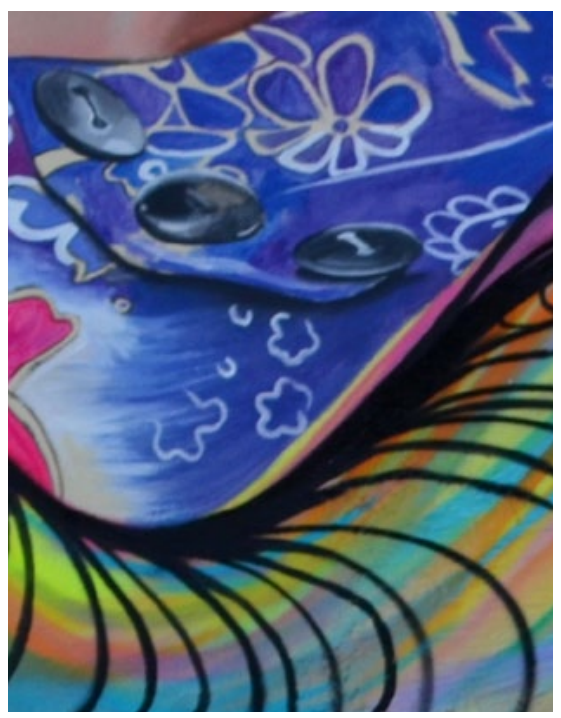

Así mismo, se debe en primera instancia hacer una rutina de pensamiento en torno a dos acciones que se viven en los centros educativos con relación a la adquisición de las TIC: la integración y la incorporación. La primera, desde un punto de vista semántico, debe entenderse como un proceso de construcción para formar un todo, mientras que la segunda es sólo una añadidura a un determinado elemento. En contexto, las TIC en la educación han pasado por un proceso de incorporación en la que sólo tiene la presencia de éstas en las instituciones (murales web, pizarrones inteligentes, plataforma de evaluaciones, entre otros). Sin embargo, las sinergias sociales han incrementado la complejidad en estos procesos y ahora es necesario no sólo la incorporación, sino la integración, por ende, se demandan procesos y protocolos institucionales más estratégicos que vinculen los procesos administrativos y curriculares (pedagógicos) de los centros educativos (Paredes, 2012).

Esta articulación de procesos, debe tener como misión el destacar y potencializar una importante virtud liberadora de fronteras de las TIC en 


\section{Las tecnologías pueden contribuir a disminuir}

\section{la inequidad y la exclusión educativa a quienes,}

\section{por diversas razones, físicas, culturales y sociales,}

no pueden gozar en igualdad de condiciones

de su derecho al conocimiento, aprendizaje

\section{y a la educación (Mesa Agudelo W. , 2012).}

educación. Es decir, tales herramientas digitales permiten el acceso, desarrollo y procesamiento de la información, sin el límite condicionado por las imposiciones espacio temporales, así mismo, promueve la interactividad y el asincronismo entre los actores educativos del centro. Estas cualidades evidencian cómo las tecnologías pueden contribuir a disminuir la inequidad y la exclusión educativa a quienes, por diversas razones, físicas, culturales y sociales, no pueden gozar en igualdad de condiciones de su derecho al conocimiento, aprendizaje y a la educación (Mesa Agudelo W. , 2012).

Actualmente, las políticas educativas realzan sus objetivos estratégicos en lograr una educación con dos cualidades centrales: calidad y equidad. Dentro de los panoramas nacionales mexicanos se pueden encontrar estos nuevos pilares sociales que debe atender la educación:

Un propósito de la Nueva Escuela Mexicana (NEM) es el compromiso por brindar calidad en la Enseñanza [...] tenemos rezago histórico en mejorar el conocimiento, las capacidades y las habilidades de los educandos en áreas fundamenta-

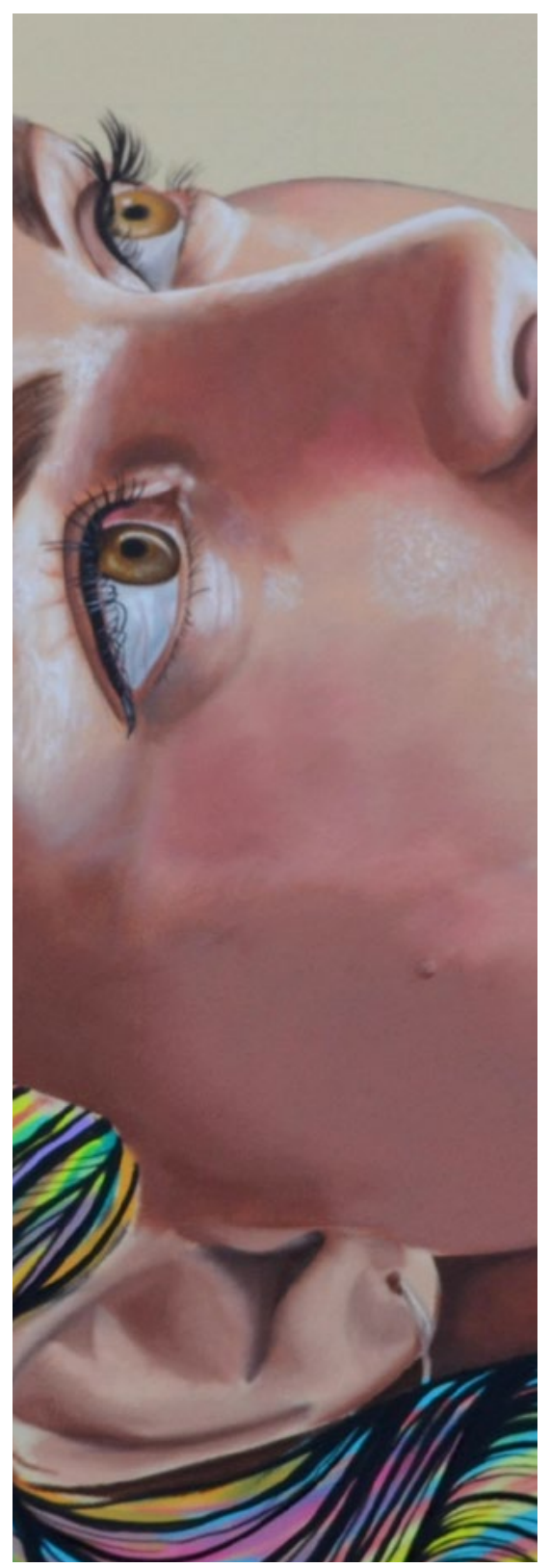

Esta nueva visión social de las instituciones educativas, es percibida a través de los medios digitales de comunicación y se sustentan en hechos claramente situados en un enfoque de comunidad. Es aquí, que los centros educativos enfrentan la fragilidad de su impacto social, frente a las rápidas notificaciones de lo que ocurre dentro de los institutos, se expone una severa falta de comunicación, acuerdos y colaboraciones entre los mismos agentes educativos y con su comunidad exterior. Así mismo, existen numerosas evidencias que las TIC por sí solas no son capaces de generar un cambio sustancial en los procesos de enseñanza-aprendizaje y transformación social, ya que la raíz de la problemática educativa es fundamentalmente humana y no tecnológica.

Con base en los panoramas generales de la educación en materia de comunidad de aprendizaje e informatización escolar, se presenta en el centro educativo que se rige bajo las legislaciones curriculares de la NEM una cultura educativa y social con carencia de visión estratégica para el mejoramiento de su servicio educativo. Debido a que no se ha atendido en primera instancia el diseño concreto del Proyecto Educativo del Centro con orientación en la aplicación de las TIC, por consiguiente, la ruta de construcción y me- 
jora socioeducativa no es perceptible para sus miembros. Lo cual ha generado consecuentemente una dispersión de la labor pedagógica de los docentes del centro; una escasa comunicación asertiva con los padres de familia; y un bajo rendimiento escolar por parte de los educandos a quienes no se les ha establecido una metodología de aprendizaje que atienda sus diversidades intelectuales y culturales.

Hoy en día, bajo los escenarios particulares de la sociedad de la información, los actos educativos ya no estriban en su totalidad de lo que se vive dentro de las aulas, ni de las interacciones que se establecen entre los agentes internos de las instituciones. Ante esto, el proyecto de Comunidades de Aprendizaje se manifiesta como una resolución que rompe con las estructuras tradicionales educativas para expandir sus prácticas a la participación de toda la comunidad global de su entorno.

Una de las ideas centrales de este concepto de CA es el de la posición consciente de los agentes educativos implicados hacia el cambio; se valora la necesidad de orientar los esfuerzos comunes hacia una mejora de la situación educativa y de aprendizaje de toda la comunidad. Es decir, al implementar los valores constructores de una CA se introducen criterios educativos más sociales y culturales, por ende, los medios digitales se adaptan e innovan para satisfacer las necesidades imperativas de interacción del conocimiento en los centros educativos. En encuadre, como lo afirman Fuentes, Zermeño y Vázquez (p. 65 2014) "relacionar la educación intercultural a la innovación tecnológica, las comunidades de aprendizaje y redes sociales,

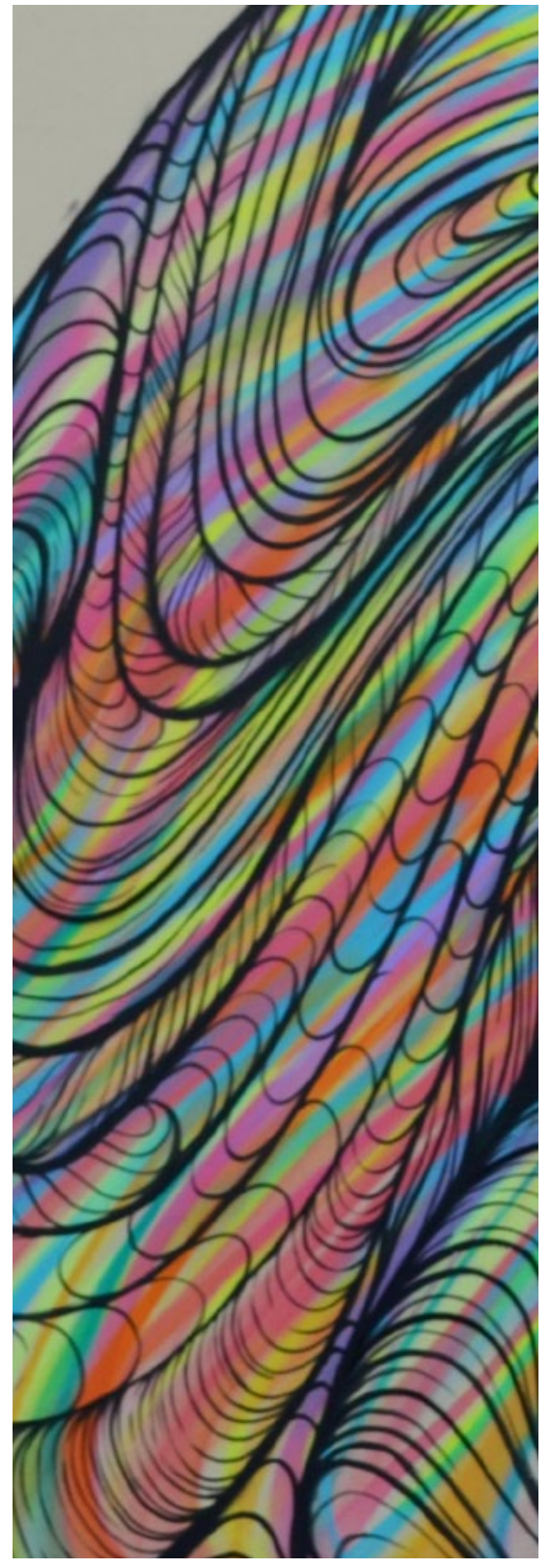

debe considerarse como una oportunidad para potencializar la adquisición y transmisión de conocimientos, partiendo del respeto, igualdad y reconocimiento".

La integración de las TIC en los centros educativos permitirá pasar de las aulas tradicionales, donde se manifiesta el aprendizaje considerado formal, a otras concepciones áulicas en las que el autoaprendizaje y la colaboración tendrán lugar.

Es aquí donde se debe capacitar el modo de facilitación de estos procesos de intercambio y crear así, un aprendizaje comunitario. Se plantea en ello el potencial que tienen las TIC para el proceso educativo, con lo que se requiere reformular la enseñanza y potencializar la colaboración entre iguales, la participación activa de los alumnos en su propio proceso de aprendizaje y al incremento de los procesos de individualización, mediante un mayor fomento de la creatividad y de la autonomía.

En este argumento, el concepto de Planeación Estratégica de la informatización de las comunidades de apren-

\section{Fuentes, Zermeño y Vázquez (p. 65 2014) "relacionar la educación intercultural} a la innovación tecnológica, las comunidades de aprendizaje y redes sociales, debe considerarse como una oportunidad para potencializar la adquisición y transmisión de conocimientos, partiendo del respeto, igualdad y reconocimiento". 


\section{Cabero (2002), menciona que en cierta medida}

\section{los nuevos medios digitales, apelan a la existencia}

\section{de una nueva disposición del proceso didáctico}

\section{y metodológico tradicionalmente usado}

\section{en nuestros centros, donde el saber no tenga por} qué recaer en el profesor, y la función del alumno

\section{no sea la de mero receptor de la información.}

dizaje infiere de un potencial importante, ya que proporciona un nuevo marco de acción para los procesos de interacción. Ahora bien, provocando un marco social que goce de mayor fluidez y adaptabilidad que los marcos tradicionales, permitiendo una diversidad de paradigmas pedagógicos en función de las necesidades interculturales de los educandos. El proceso de la PE se desarrolla en 6 fases:

1. Fundamentos de la Planeación Estratégica.

2. Conocimiento Competitivo y Organizacional.

3. Formulación de la Estrategia.

4. Implementación de la Estrategia.

5. Ejecución de la Estrategia. Monitoreo de las acciones emprendidas bajo la misma meta objetiva.

6. Evaluación Estratégica.

La mediación estratégica de las TIC ofrece la posibilidad de organizar ambientes significativos de aprendizaje desde el trabajo personal y colaborativo, lo cual requiere materiales diseñados que estimulen la reflexión crítica y social frente al nuevo conocimiento. En relación a lo planteado, los nuevos medios digitales, apelan a la existencia de una nueva disposición del proceso didáctico y metodológico tradicionalmente usado en nuestros centros, donde el saber no tenga por qué recaer en el profesor, y la función del alumno no sea la de mero receptor de la información.

En concreto, la Planeación Estratégica para la gestión de la informatización de la CA de los centros educativos atiende las acciones de mejora pertinentes para evolucionar de una sociedad de la información a la de una sociedad del conocimiento.

El objetivo general es elaborar un Plan Estratégico Institucional para la

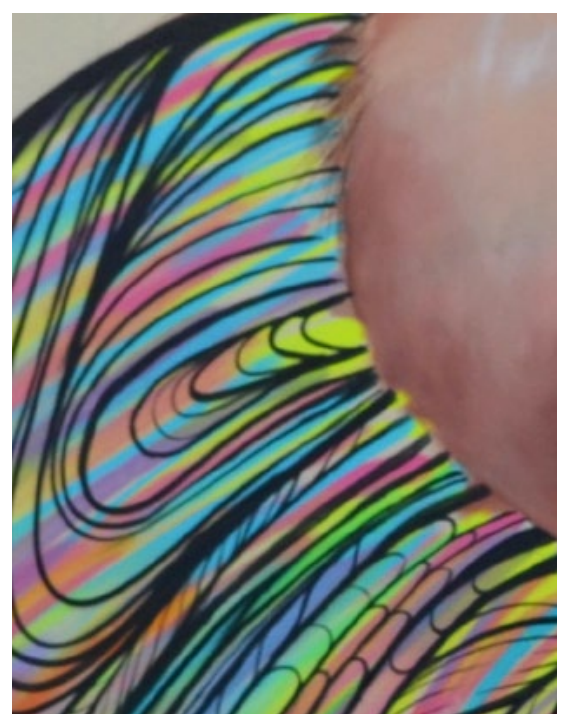

gestión de la integración de las herramientas digitales en la Comunidad de Aprendizaje de un centro educativo, mediante la adaptación didáctica del profesorado que permita potencializar las experiencias de aprendizaje del centro hacia su comunidad.

\section{OBJETIVOS ESPECIÍFICOS}

- Realizar el Análisis Estratégico (FASE I), con el diagnóstico y clarificación de las metas e indicadores de calidad a lograr.

- Formular la Estrategia (FASE II), a través de convenios con instituciones de carácter digital para implementación de recursos TIC, así como la capacitación al profesorado para su uso pedagógico.

- Implementar el Plan Estratégico (FASE III), mediante la aplicación de las herramientas digitales y diseñar actividades académicas de indagación y de colaboración entre estudiantes y profesores.

\section{METODOLOGÍA DOCUMENTAL}

El presente proyecto de investigación se aborda desde un estudio documental que aborda revisiones críticas del estado del arte, la integración, organización y evaluación teórica y empírica

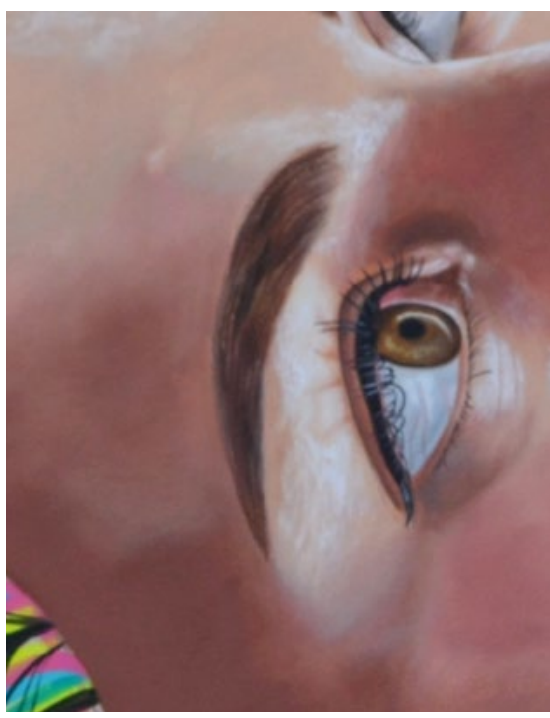




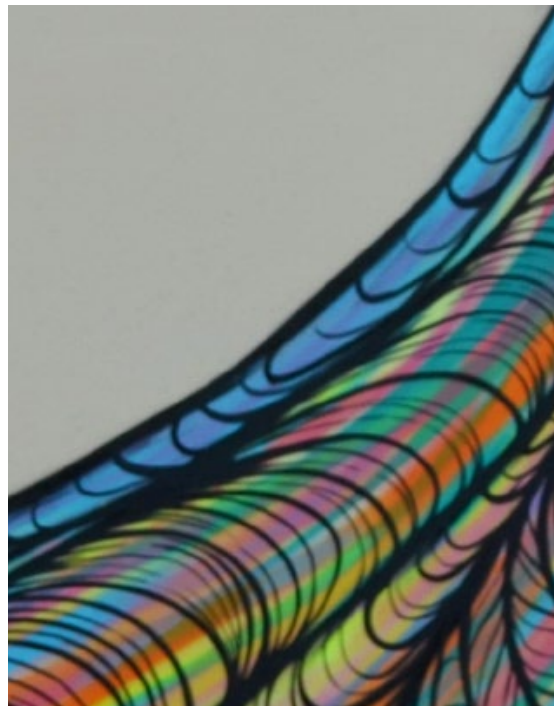

existente sobre el fenómeno a desarrollar: la Planeación Estratégica para la Informatización de una Comunidad de Aprendizaje.

Como primer enfoque de esta investigación documental, se desarrolla el planteamiento y delimitación del fenómeno de la PE, la informatización y la consolidación de las CA. Esto se determinó con base en la revisión de literatura previa en donde se encuadran los problemas contextuales de la educación actual.

En concordancia a lo procedimental, se parte de dos fundamentos de estados del arte: la heurística o de recolección de fuentes de información, y la hermenéutica o de análisis.

En la primera fase, en este momento, se establecieron los protocolos y criterios de búsqueda y revisión de fuentes de información como estrategia que favorece un desarrollo coherente y contextualizado a la PE en México, las legislaciones educativas nacionales, las concepciones culturales de las CA mexicanas, entre otros (Budgen y Brereton, 2006, citados en Barbosa, 2013). En este mismo plano, se establece un

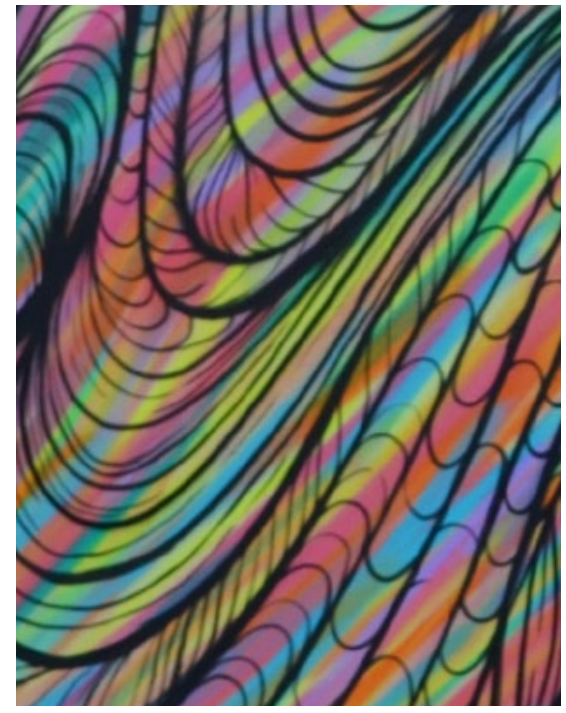

protocolo basado en los indicadores de Barbosa (2013) en el que se estructuraron 5 criterios:

- El idioma de las fuentes de información (español).

- El periodo de tiempo (20102020).

- La generación de los términos de búsqueda (construcción a partir de definiciones y concepciones).

- Los recursos posibles de provisión de fuentes de información (artículos electrónicos, tesis doctorales, Google Académico, REDALyC, Biblioteca UNIR).

- La propuesta de estrategias particulares para la búsqueda de di- chas fuentes (establecer normas de revisión y criterios de inclusión y exclusión).

Para el desarrollo de esta investigación documental, se recurrió a la obtención de información en fuentes primarias, secundarias y terciarias. Comenzando con las fuentes terciarias, se realizó la revisión de literatura general y etimológica en diccionarios y enciclopedias sobre las concepciones de la planeación, de la estrategia, de las estructuras administrativas, estructuras sociales de aprendizaje, entre otros conceptos. Posteriormente se revisó la documentación secundaria con la lectura de artículos editoriales que expresaran las inquietudes de las planeaciones estratégicas y la informatización de los centros escolares, que servirían de guía para llegar a la revisión y análisis de los documentos primarios, los cuales abarcaron otros proyectos similares como algunas tesis de posgrado, artículos de la red educativa particulares del análisis de las TIC educativas y la PE escolar.

En un segundo momento se desarrolla la fase hermenéutica, la cual representa el trabajo de lectura de análisis, 
interpretación y comprensión crítica y objetiva en acuerdo con los propósitos de la investigación. Esta fase permite ampliar marcos de referencia sobre el estudio en particular y es en donde se realiza un trabajo crítico que proporciona la identidad de la literatura al fenómeno de la presente investigación (Barbosa Chacón, Barbosa Herrera y Rodríguez Villabona, 2013).

Para el desarrollo de esta fase se enmarca el énfasis en el compromiso por el análisis e interpretación de la literatura. Del mismo modo, basado en el modelo propuesto por Barbosa (2013), el procedimiento de análisis documental se llevó a cabo de la siguiente manera:

- Ordenamiento y manipulación de la información en sus fuentes y resumen de datos (categorización de documentos en primarios, secundarios y terciarios, como se estableció en la fase anterior).

- Escritura detallada de categorías y relaciones entre éstas (establecimiento de temas y subtemas en correlación entre sí).

- Afinamiento de la búsqueda de categorías centrales (categorización de los tres elementos cen-

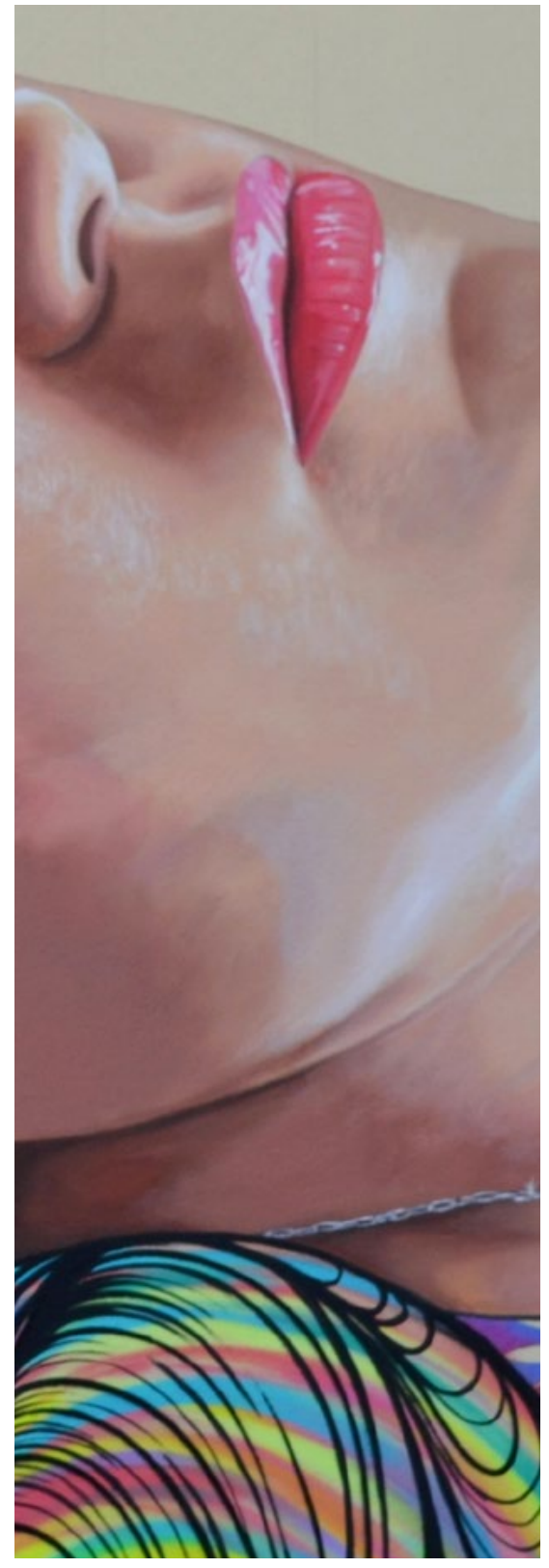

DE UNA COMUNIDAD DE APRENDIZAJE

trales de la investigación: la PE, la Informatización y las (A).

- Texto analítico final (desarrollo del marco teórico, conceptual, referencial y contextual).

\section{PROPUESTA METODOLÓGICA}

Para la presente práctica metodológica, se propone el modelo de investigación-acción, esto debido a la naturaleza social y educativa que acontece el proyecto. Otra característica de esta investigación es la integración de líneas de acción. El centro de este proyecto es la PE para lograr un cambio 0 , en medida posible, una mejora en las prácticas sociales educativas del centro escolar. En conjunto con la PE, la investigación-acción según las premisas de Murillo (2010), pretende comprender e interpretar las prácticas sociales (indagación sistemática, crítica y pública) para cambiarlas (acción informada, comprometida e intencionada) y mejorarlas (propósito valioso). Para afinidades de este proyecto de investigación, la modalidad crítica emancipadora funge como enfoque contextual.

\section{ENFOQUE DE LA INVESTIGACIÓN: CUANTITATIVO}

Se propone el enfoque cuantitativo como modelo para esta investigación debido a que se alinea a la naturaleza secuencial de la PE del caso. Los estudios cuantitativos que presenta la investigación mantienen un patrón estratégico predecible y sustentado. Esta orientación hace uso del razonamiento lógico-deductivo, que comienza con la teoría y conlleva a la praxis y comprobación de posibles resultados (Hernández Sampieri, et al, 2010).

Tal como se revisó en apartados anteriores, el fenómeno de la investiga- 
ción de la PE es acompañado de una revisión de literatura teórica y documental para estructurar las líneas de acción en donde se buscan alcanzar la realización de sus objetivos.

Así mismo, cuando se habla de planteamientos metódicos y estratégicos, es necesaria la comprensión o tener la mayor cantidad de información sobre la realidad objetiva del fenómeno. Es así como se obtiene una visión realista y concreta del fenómeno (PE) y los eventos que la rodean a través de sus manifestaciones (entre los diversos factores educativos y culturales de una $(A)$ y para entender el porqué de las cosas, es necesario registrar y analizar (documentar) dichos eventos.

Cabe mencionar, como lo expresan Hernández Sampieri, et al (2010), en el enfoque cuantitativo lo subjetivo existe y posee un valor para los investigadores; pero de alguna manera este enfoque se aboca a demostrar qué tan bien se adecua el conocimiento a la realidad objetiva. Es por ello que documentar esta coincidencia constituye un propósito central de muchos estudios cuantitativos.

En una investigación cuantitativa se pretende generalizar los resultados encontrados en un grupo o segmento (docentes y estudiantes) a una colectividad mayor (CA). Así mismo, se procura que los estudios efectuados puedan replicarse con su respectiva adecuación a los diversos contextos interculturales de cada centro educativo. Tal cual ocurre con la PE, en los estudios cuantitativos, se quiere ofrecer recomendaciones aplicables a una población más amplia para orientar la posible solución de problemas similares o toma de decisiones estratégicas.

\section{Hernández Sampieri, et al (2010), en el enfoque} cuantitativo lo subjetivo existe y posee un valor para los investigadores; pero de alguna manera este enfoque se aboca a demostrar qué tan bien se adecua el conocimiento a la realidad objetiva.

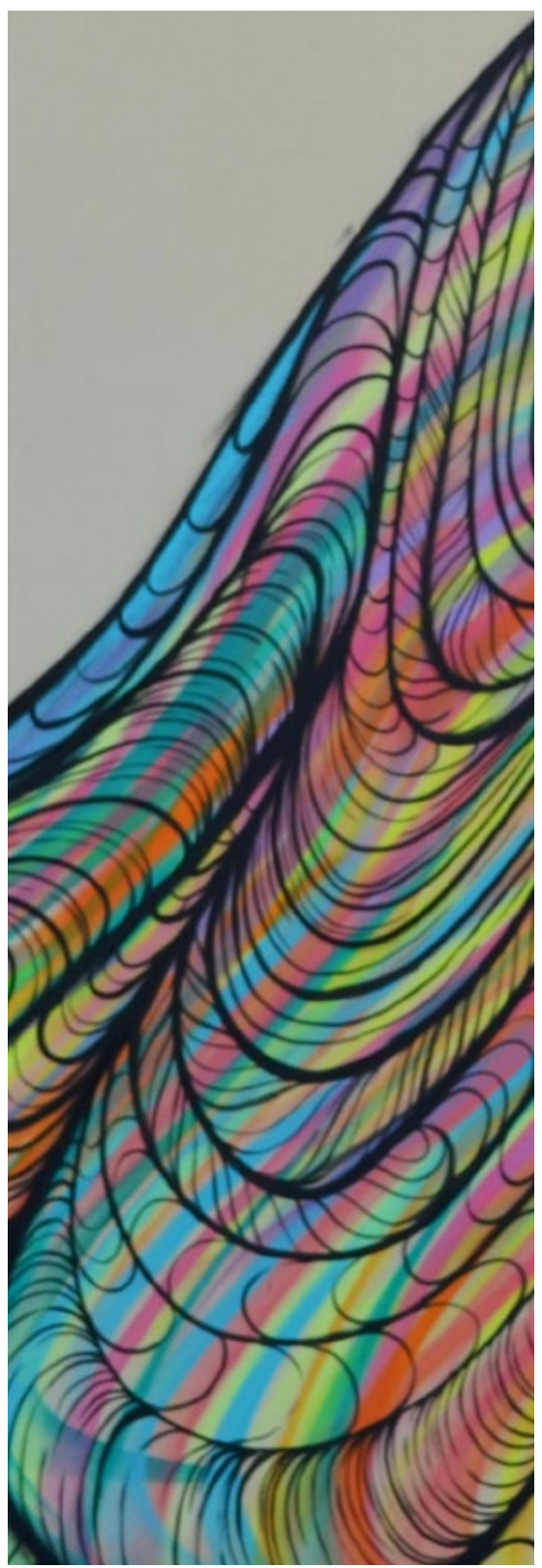

\section{TIPOLOGÍA Y DISEÑO}

\section{DE LA INVESTIGACIÓN}

La presente investigación desarrollará unos estudios de carácter exploratorio. Si bien es cierto que ya existen concepciones previas de lo que es una Planeación Estratégica y una Comunidad de Aprendizaje, los estudios exploratorios sirven para obtener información sobre la posibilidad de llevar a cabo una investigación más completa respecto de un contexto particular, en este caso, la informatización de una CA; investigar nuevos problemas, como lo son la diversidad intelectual e intercultural para abordar los procesos de E-A con aplicación a las TIC; $y$, establecer prioridades para investigaciones futuras, o sugerir afirmaciones y postulados, como lo es el hecho de que la PE siempre estará en constante adaptación y valoración.

De este modo los estudios exploratorios en pocas ocasiones constituyen un fin en sí mismos, generalmente determinan tendencias, identifican áreas, ambientes, contextos y situaciones de estudio; 0 establecen el tono de investigaciones posteriores más elaboradas y rigurosas. Estas indagaciones se caracterizan por ser más flexibles 
en su método en comparación con las descriptivas, correlacionales 0 explicativas, y son más amplias y dispersas (Hernández Sampieri, et al, 2010).

Ya establecido el planteamiento del problema, el enfoque cuantitativo, el alcance exploratorio y los lineamientos de investigación -en donde cabe señalar que no se presentan hipótesis debido a la naturaleza del estudio- se debe visualizar de manera práctica y concreta cubrir los objetivos establecidos en el presente proyecto. Para ello, se requiere de un diseño de investigación, que sirva como plan 0 estrategia que se desarrolla para obtener la información necesaria en una investigación.

Con base a lo anterior, y partiendo de las líneas de la investigación-acción, se plantea el modelo de Kemmis (1989). Este proceso se organiza sobre dos ejes: uno estratégico, constituido por la acción y la reflexión; y otro organizativo, constituido por la planificación y la observación. Ambas dimensiones están en continua interacción, de manera que se establece una dinámica que contribuye a resolver los problemas y a comprender las

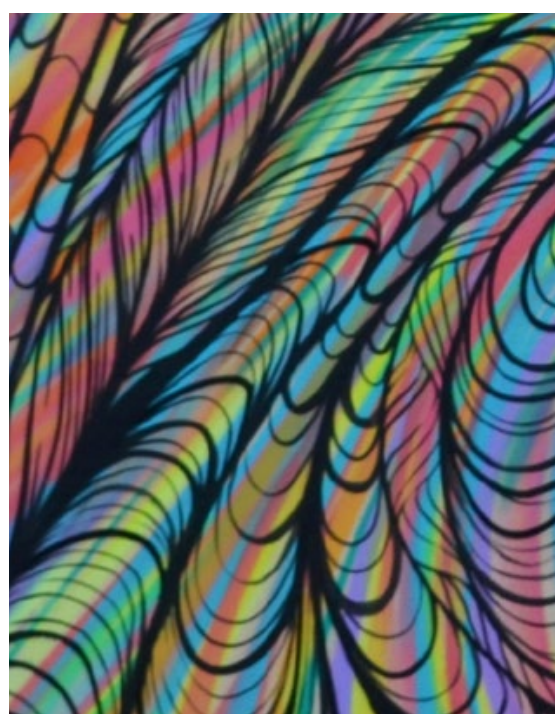

Se abordan procesos de reflexión sobre las nuevas funciones sociales que los centros educativos deben cubrir para mantener su filosofía sustancial: el aprendizaje y formación de ciudadanos.

prácticas que tienen lugar en la vida cotidiana de la escuela (Murillo Torecilla, 2010). En este modelo, la PE y su implementación serán de orientación metodológica para realizar, lo que en otro momento se señaló, como el modelo o ciclo de Deming (1950). Esto se evidencia más en las 4 fases que integran de manera interrelacionada este proceso:

1. Planificación.

2. Acción.

3. Observación.

4. Reflexión.

Las líneas propuestas para la acción metodológica que expresan el desa-

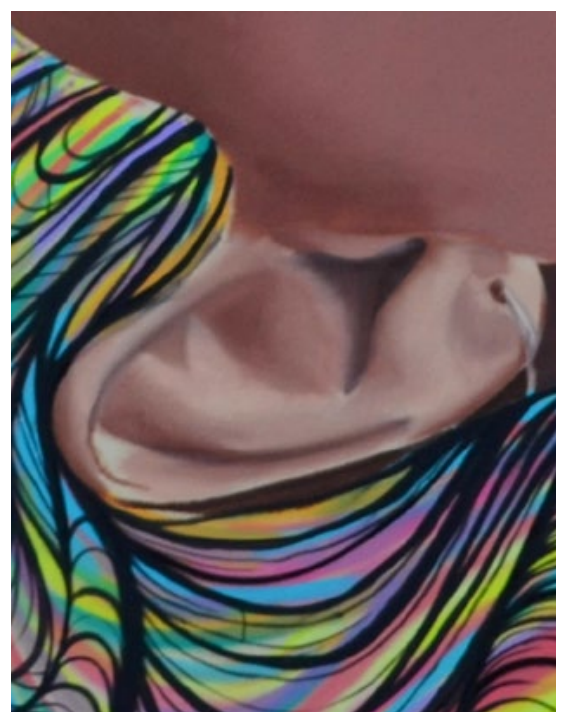

rrollo del presente proyecto serán bajo las fases de Planeación Estratégica. Se abordarán las fases del diagnóstico institucional, el establecimiento de metas mesurables, el planteamiento de estrategias, el monitoreo del desarrollo de las estrategias y, por último, la evaluación estratégica.

\section{RESULTADOS DE LA INVESTIGACIÓN DOCUMENTAL}

Hoy en día los panoramas educativos están inmersos en una sociedad dinámica en lo que a procesos culturales, políticos y sociales se refiere. Con base en esto, se abordan procesos de reflexión sobre las nuevas funciones sociales que los centros educativos deben cubrir para mantener su filosofía sustancial: el aprendizaje y formación de ciudadanos.

Bajo el contexto de la sociedad de la información y del conocimiento que la globalización del siglo XXI ha estimulado en nuestro entorno, la presente investigación documental ha presentado un análisis de aquellos componentes que proponen estructurar líneas de acción para la integración de las competencias que todo individuo necesita para su integración social y 
profesional. En la presente propuesta, se expresan los sustantivos de Planeación Estratégica, Informatización y Comunidades de Aprendizaje, en los cuales, la investigación documental desenvuelve la interrelación entre estos elementos.

Partiendo de esta premisa, se puede inferir que en la interacción entre estos objetos de estudio se encuentra el mapeo analítico del sector educativo para atender y lograr la revalorización de la escuela como motor de cambio en la sociedad actual.

La PE promete entablar bajo una óptica sustentada en la observación, reflexión y colaboración, una serie de acciones y conductas que permitirán orientar a todos los agentes educativos y sociales adaptarse y ser competentes en el mercado actual.

Se ha expresado por diversos autores las líneas conceptuales de la informatización de los centros educativos. De ello se destaca la importancia de desarrollar una innovación en los paradigmas educativos para la integración total de las TIC, tales modificaciones deben atender desde el currículum

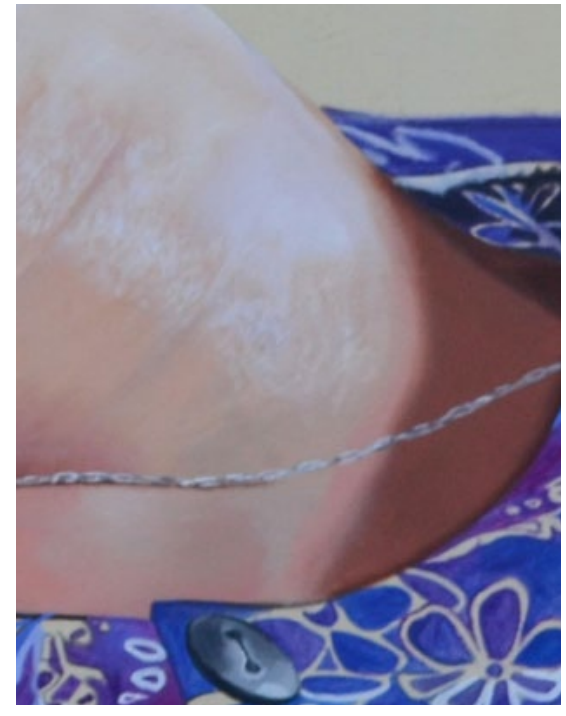

hasta las didácticas y las experiencias de aprendizaje de los educandos, profesores, PAS y comunidad externa del centro educativo.

Del mismo modo, se infiere a través del análisis documental-contextual de las CA que los agentes que intervienen en las experiencias de aprendizaje deben considerar una alineación axiológica y conductual sobre los modos de ver, entender y actuar el aprendizaje.

\section{VALORACIÓN \\ DE LA PLANEACIÓN ESTRATÉGICA}

La valoración objetiva de la PE se presenta bajo el escenario de la in-
Partiendo de esta premisa, se puede inferir

que en la interacción entre estos objetos de estudio se encuentra el mapeo analítico del sector educativo para atender y lograr la revalorización de la escuela como motor de cambio en la sociedad actual.

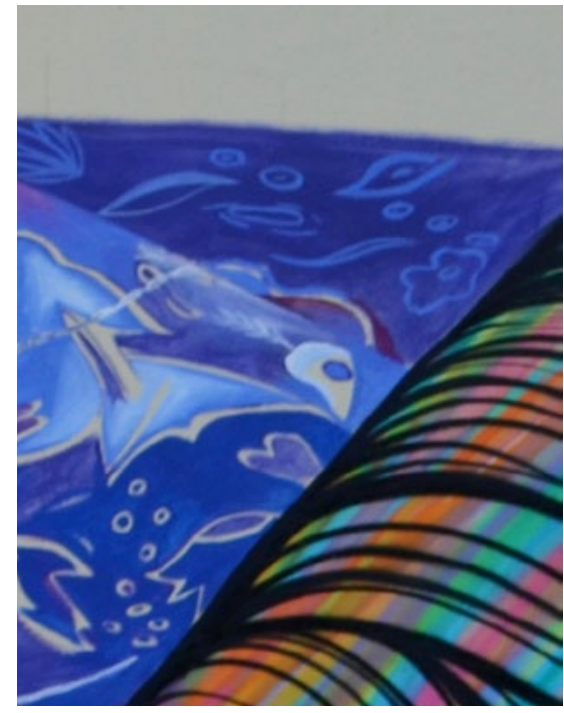

vestigación documental, y con ello la propuesta metodológica de la acción se realiza con base en el cumplimiento de los objetivos planteados en la investigación que abordan el diseño instrumental y no la total ejecución de la PE propuesta.

Como objetivo general se expone la finalidad de diseñar un documento rector de planeación para lograr integrar las TIC educativas a un centro escolar. Ante ello, se expresa el cumplimiento de este objetivo con el desarrollo de una propuesta metodológica con un sustento documental. Además, se abordaron las exploraciones conceptuales sobre las Comunidades de Aprendizaje y las metodologías didácticas actuales que permitieron destacar la relevancia social que se imprime en la presente PE.

Por otro lado, como objetivos específcos se expresaron el desarrollo de tres fases estratégicas para el diseño de la propuesta metodológica. Para la Fase I (realizar el análisis estratégico: diagnóstico y establecimiento de objetivos mesurables), el objetivo se logró debido a las propuestas instrumentales como el diagnóstico FODA, investiga- 


\section{Los análisis documentales que se desarrollan}

\section{para el diseño de la PE, aportan una línea}

de acción estratégica que reduce drásticamente

las posibilidades de errar y obstaculizar

los objetivos mediante el sustento teórico

y conceptual de lo estratégico.

ción documental histórica del centro educativo, y el apego a los indicadores de la legislación mexicana para orientar el diagnóstico contextual del colegio.

En cuanto a la Fase II (formular la estrategia: convenios, recursos y desarrollo del capital humano), la propuesta metodológica con sustento teórico y conceptual expresan la concreción de este objetivo debido a que se exponen los elementos de la alineación estratégica y la vinculación estratégica, en la que ambas cuentan con el desarrollo concreto de líneas de acción y agentes con quien se pueden llevar a cabo.

Como último objetivo, la implementación de la PE (Fase III), se observa su cumplimiento con el desarrollo de políticas educativas y rúbricas que permitirán el monitoreo y concordancia con los aspectos identitarios del centro escolar y su comunidad de aprendizaje.

Como se infiere, la PE que aquí se desarrolla, es un elemento que sin duda plantea a conciencia el diseño de acciones que expresan en sí mismas

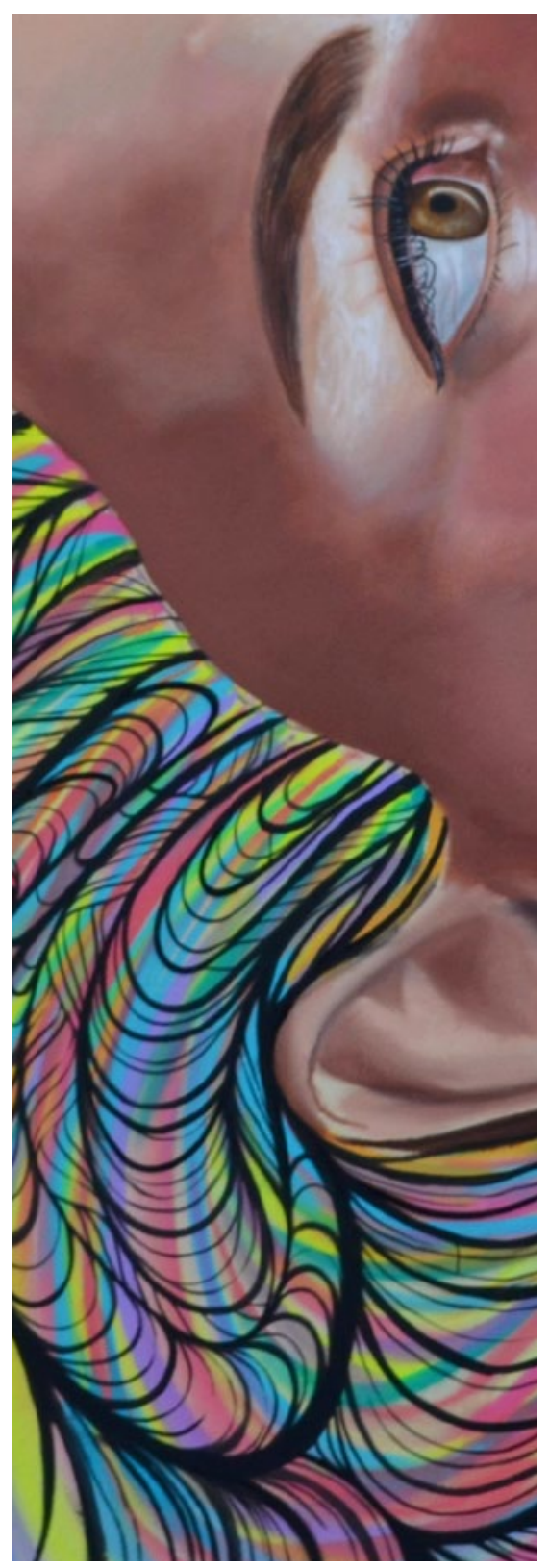

los elementos identitarios del centro educativo. Proporciona las rutinas de pensamiento crítico para el diseño estratégico de comportamientos de los agentes educativos que están inmersos en la innovación pedagógica.

Los análisis documentales que se desarrollan para el diseño de la PE, aportan una línea de acción estratégica que reduce drásticamente las posibilidades de errar y obstaculizar los objetivos mediante el sustento teórico y conceptual de lo estratégico. A través de este análisis documental, se reflexiona sobre las repercusiones sociales que se demandan hoy en día en los centros educativos, y con ello, resaltar la imperante necesidad de una transformación de paradigmas educativos que satisfagan las competencias en las redes de información y conocimiento que la globalización ha presentado.

Esta propuesta podría servir como punto de partida hacia ese gran reto de crear espacios de aprendizaje que fortalezcan las interacciones entre los agentes educativos y con ello consolidar una comunidad de aprendizaje competente en la sociedad de la información y el conocimiento.

\section{CONCLUSIONES}

La planeación estratégica de un proceso de integración de TIC en la educación de una comunidad de aprendizaje, a pesar de no ser una garantía de éxito, si garantiza la mayor coherencia y pertinencia del proyecto educativo adecuado a sus cualidades de gestión interna y externa, y su responsabilidad social para con su entorno. Así mismo, garantiza una mejora significativa en los factores de calidad que demandan las sociedades globales de hoy en día. 


\section{La planeación estratégica de un proceso}

\section{de integración de TIC en la educación}

\section{de una comunidad de aprendizaje, a pesar}

de no ser una garantía de éxito, si garantiza

la mayor coherencia y pertinencia

del proyecto educativo.

En cierto modo, la PE promueve una educación de calidad y equidad ya que la integración meditada de las tecnologías educativas disminuye la brecha entre la diversidad intelectual e intercultural que interactúan en un centro educativo. Además de esto, la adaptabilidad curricular en tecnología me- diante el empleo de esta PE, visiona la consolidación de un aprendizaje en comunidad haciendo un uso favorable de esta diversidad de inteligencias.

Ante las demandas neoliberales que tienen que cubrir los centros educativos, la Planeación Estratégica Escolar

debe comenzar a diseñar e implementar paradigmas estratégicos educativos que atiendan las diferencias peculiares del sector empresarial con el de la naturaleza educativa. Es por ello que esta línea de investigación queda disponible para la expansión del conocimiento. Será necesario diseñar modelos de planeación educativa estratégica que aborde las nuevas interacciones políticas, sociales e interculturales del mundo actual.

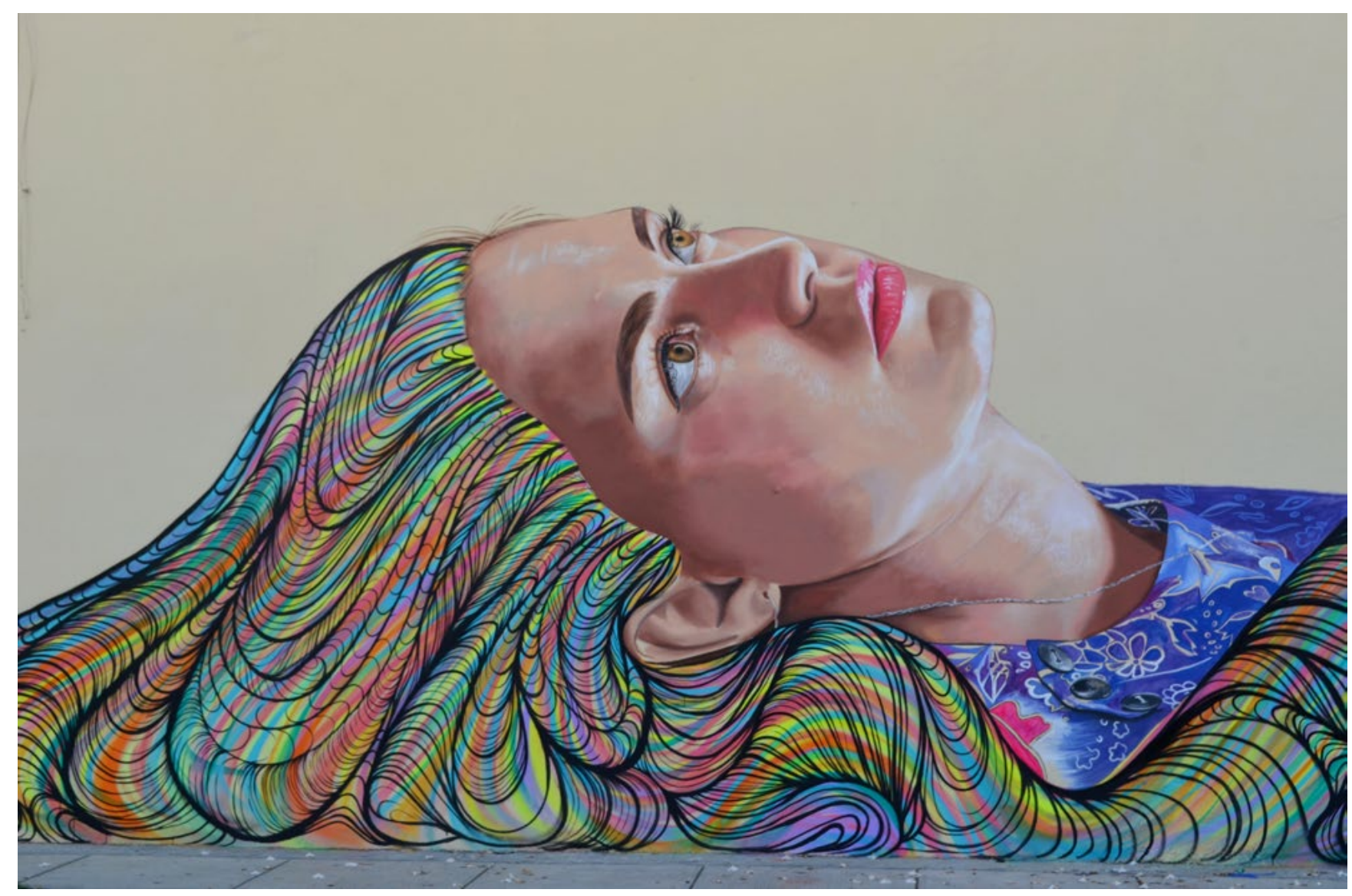




\section{REFERENCIAS}

Barbosa Chacón, J.W., Barbosa Herrera, J. C., y Rodríguez Villabona, M. (2013). Revisión y análisis documental para estado del arte: una propuesta metodológica desde el contexto de la sistematización de experiencias educativas. INVESTIGACIÓN BIBLIOTECOLÓGICA, UNAM, 27(61), 83-105. Recuperado el 29 de junio de 2020, de https://reader.elsevier.com/reader/sd/pii/S0187358X13725553?token=EE8AED5038B455F5F92747304E9F6351E7FA5AE6FE19A288F721A63D2FEED0A5B683155F7CD1EB79AEBCD42BF2E598AC

De la Herrán, A., y Fortunato, I. (2017). La clave de la educación no está en las nuevas Tecnologías de la Información y la Acta Scientiarum. Education, 39(3), 312. Recuperado el 25 de Abril de 2020, de https://www.redalyc.org/ pdf/3033/303351030008.pdf

Fuentes, C., Zermeño, M., y Vázquez, N. (2014). Comunidades de aprendizaje y redes sociales: una estrategia para promover la interculturalidad y la identidad. Cuadernos Interculturales, 1 (22), 61 - 74. Recuperado el 27 de abril de 2020, de https://www.researchgate.net/publication/266315868_Comunidades_de aprendizaje_y redes sociales_una_estrategia_para_promover la interculturalidad_y la identidad

Hernández Sampieri, R., Fernández Collado, C., y Baptista Lucio, M. d. (2010). Metodología de la investigación (Quinta edición ed.). (J. Mares Chacón, Ed.) México: McGRAW-HILL / INTERAMERICANA EDITORES, S.A. DE C.V.

Mesa Agudelo, W. (2012). Las TIC como herramientas potenciadoras de equidad, pertinencia e inclusión educativa. Trilogía Ciencia Tecnología Sociedad, 4(7), 6075. De https://doi.org/10.22430/21457778.153

Murillo Torecilla, F. J. (2010). Investigación Acción. Métodos de investigación en Educación, 3-26. Recuperado el 27 de Junio de 2020, obtenido de https://d1watxts1xzle7.cloudfront.net/39407277/rodriguez_s investigacion accion.pdf? $1445752595=$ \& response-content-disposition=inline $\% 3 \mathrm{~B}+\mathrm{fi}-$ lename\%3DRodriguez s investigacion_accion.pdf\&Expires $=1593301272 \&$ Signature=GOvskKkewvXbiYOBhDgDhNNoNHH93rFn-EP87JUZmXJg

Paredes, H. (2012). Tic en Educación: Planeación Estratégica. SIRED, 1-10. Recuperado el 25 de abril de 2020, de http://sired.udenar.edu.co/185/

Secretaria de Educación Pública (2019). La Nueva Escuela Mexicana: principios y orientaciones pedagógicas. Recuperado de http://cetis22.edu.mx/assets/ pdf_pedagogicas_nem.pdf

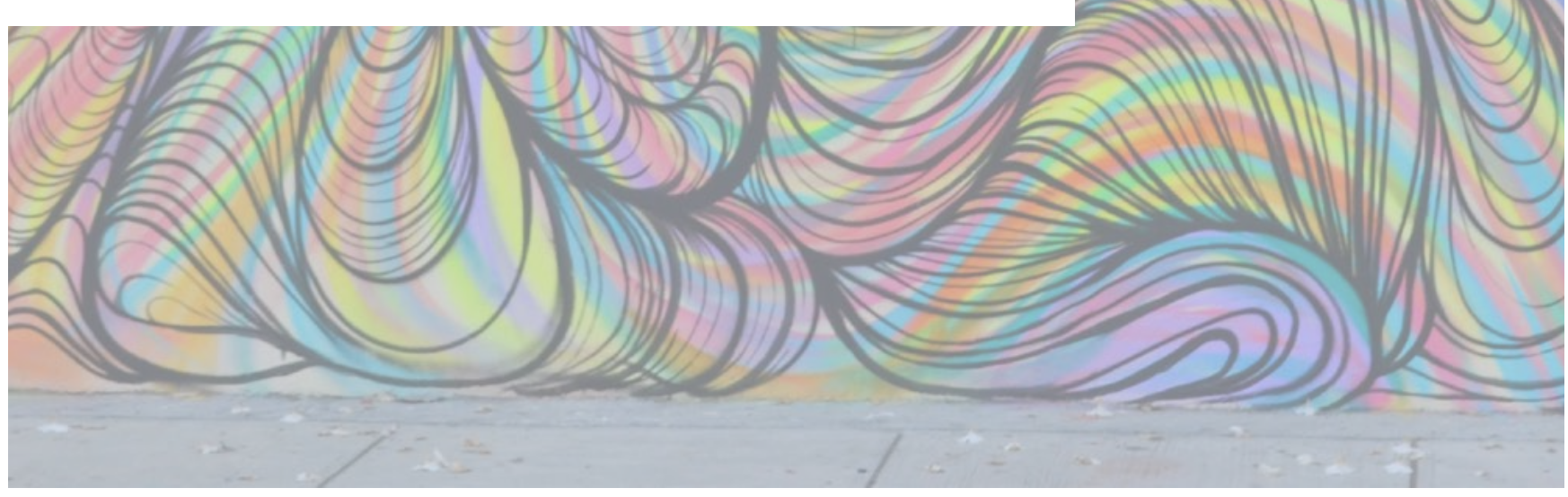



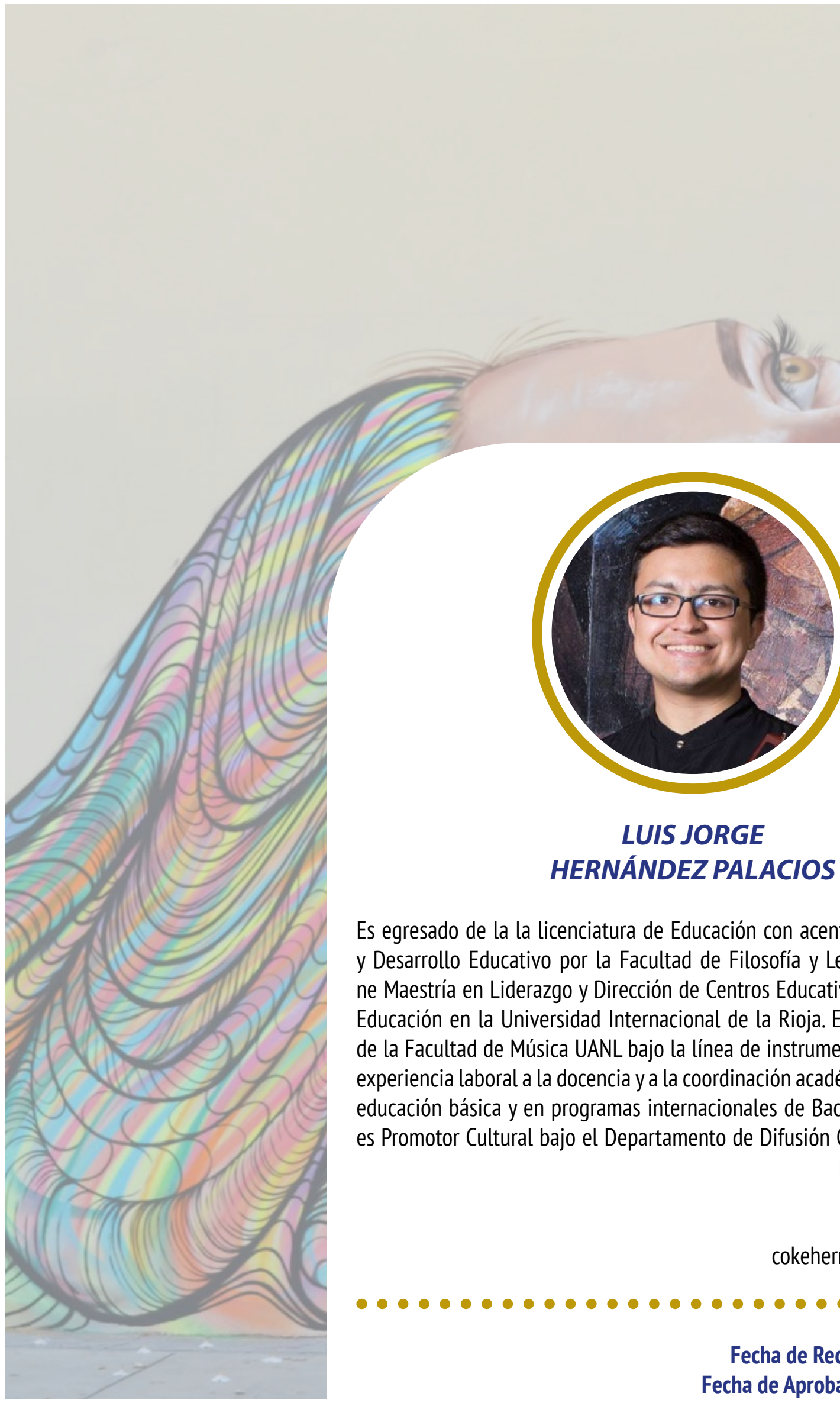

Es egresado de la la licenciatura de Educación con acentuación en Planeación y Desarrollo Educativo por la Facultad de Filosofía y Letras de la UANL. Tiene Maestría en Liderazgo y Dirección de Centros Educativos por la Facultad de Educación en la Universidad Internacional de la Rioja. Es egresado así mismo de la Facultad de Música UANL bajo la línea de instrumentista. He dedicado su experiencia laboral a la docencia y a la coordinación académica en los niveles de educación básica y en programas internacionales de Bachillerato. Actualmente es Promotor Cultural bajo el Departamento de Difusión Cultural de la SE en el Estado de Nuevo León.

Correo Electrónico: cokehernandez94@gmail.com

Fecha de Recepción: Octubre 2020 Fecha de Aprobación: Diciembre 2020 


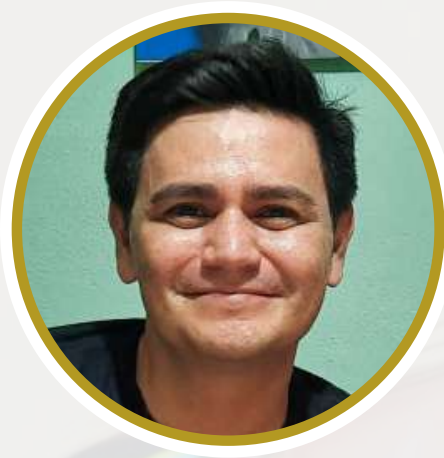

\section{Carlos Enrique Robledo Moreno, 1981, Monterrey, Nuevo León}

Artista egresado de la Facultad de Artes Visuales de la Universidad Autónoma de Nuevo León. La mayor parte de su obra la realiza en murales por las principales avenidas del municipio de San Nicolás de los Garza, Nuevo León, México. Coordina el programa de Arte Urbano en el Instituto Municipal para el Desarrollo Cultural (IMDEC) de San Nicolás de los Garza. Además, realiza su obra en lienzo y en el arte Madonnari (gis/pavimento). Ha expuesto y pintado de manera local, nacional e internacionalmente en paises como Francia, Italia y Estados Unidos. Ha recibido importantes reconocimientos como en Nocera Superiore, Italia, 2013 (2do. lugar del público) y 2015 (1er lugar del público); y en Wilhelmshaven, Alemania, 2019 (3er Lugar Categoría Libre).

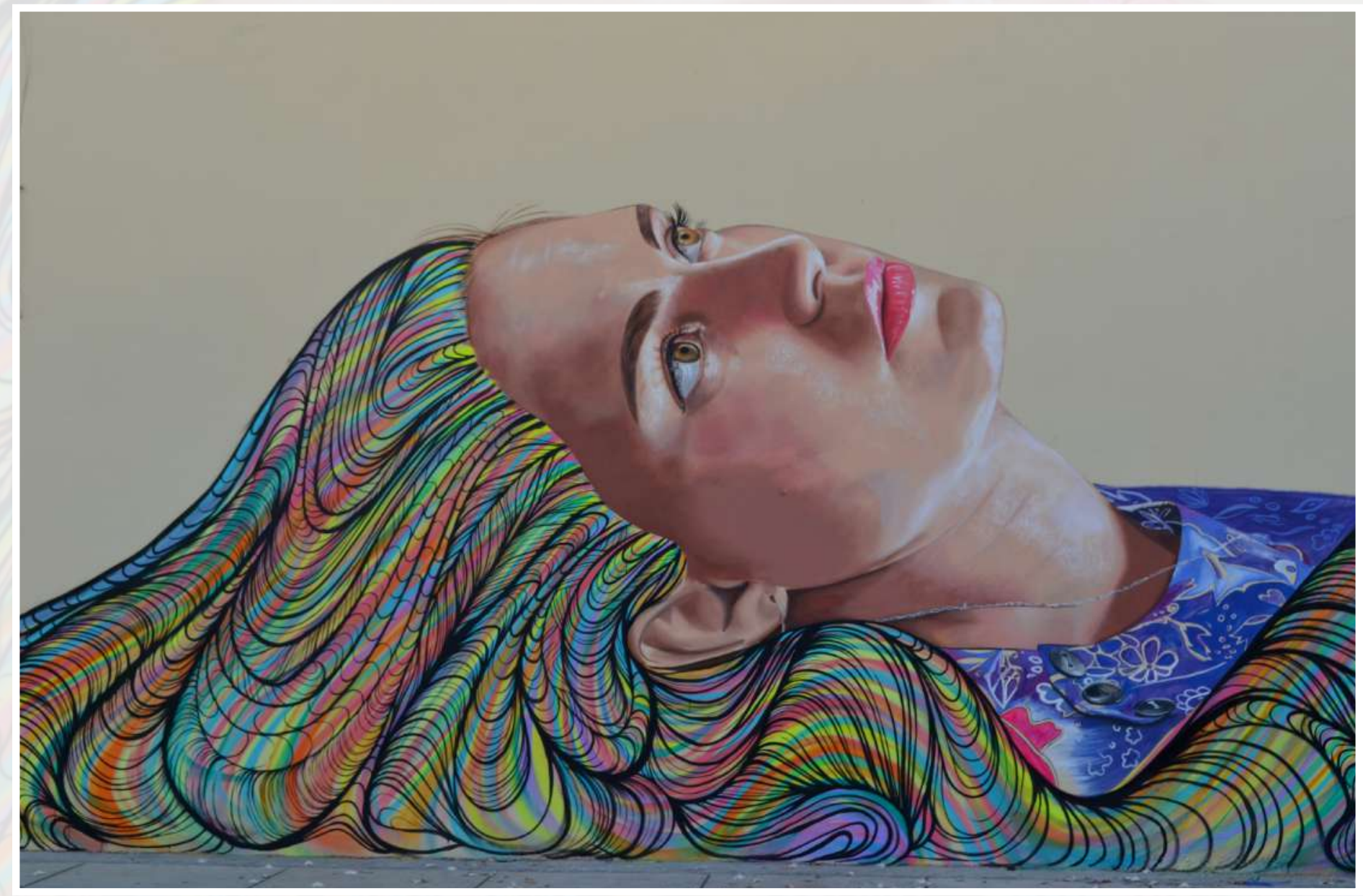

Como artista visual plasmo el retrato y figura humana realista, en conjunto con una simbología acorde a la temática de la obra. Me gusta ver mi obra como todo un proceso, el cual va desde la idea, el boceto, la elección del o la modelo, la toma de una fotografía o bien un dibujo, hasta la realización de la pintura. Generalmente utilizo el acrílico por la rapidez con la que puedo realizar obras en tonos vivos y cálidos. Pienso que en el discurso de la obra que realizo, trato hacer conciencia de lo caótico de la ciudad, del ser humano en sí y de la interacción del individuo con la naturaleza.

\section{- Carlos Robledo}

